\title{
Relationship Between Consanguineous Marriages and Incidence and Severity of Refractive Errors: A Cross-sectional Study
}

\author{
Ali Mazyed Alsaqr \\ Department of Optometry, College of Applied Medical Sciences, King Saud University, Riyadh, Saudi Arabia \\ Email address: \\ aalsaqr@ksu.edu.sa

\section{To cite this article:} \\ Ali Mazyed Alsaqr. Relationship Between Consanguineous Marriages and Incidence and Severity of Refractive Errors: A Cross-sectional \\ Study. International Journal of Ophthalmology \& Visual Science. Vol. 4, No. 4, 2019, pp. 81-87. doi: 10.11648/j.ijovs.20190404.15
}

Received: October 7, 2019; Accepted: October 26, 2019; Published: November 5, 2019

\begin{abstract}
Congenital and genetic ocular disorders are linked to parental consanguinity. The aims was to investigate the effects of consanguineous marriages on the refractive errors of preschool-aged and adolescent patients. Two sample groups were recruited: the preschooler group (3-6 years; 335 participants) and the adolescent group (12-20 years; 998 participants). The required sample size was calculated using a sample size estimation software. Visual acuity was measured using the 15-line Lea symbols chart in the pre-school aged group and non-illuminated ETDRS VA chart in the adolescent group. Spherical equivalent refractive errors were noted with near-retinoscopy technique in young children and with the ARK-30 autorefractor in the adolescent group. In order to explore the impact of consanguineous marriages, the data were analyzed separately based on the age group using SPSS version 21 software. In the preschooler group, myopia was found in $4.2 \%$, hyperopia in $8.1 \%$, and astigmatism in $20 \%$. Three children had high myopic scores $(-10.00 \mathrm{D},-13.50 \mathrm{D}$ and $-17.50 \mathrm{D})$. In the adolescent group, $45.6 \%$ participants were myopic, $3.8 \%$ were hyperopic, and $22.3 \%$ were astigmatic. Despite the higher frequency of RE in those 15 years and older in the cousins group and the consanguineous parents of the three preschool-aged children with high myopia, there were no statistically significant $(p>0.05)$ evidence that consanguineous marriages impact the refractive errors of their children. In conclusion, despite previous studies showing a link between ocular genetic or congenital disorders and consanguinity, no such link could be established with regard to refractive errors.
\end{abstract}

Keywords: Consanguinity, Consanguineous Marriages, Refractive Errors, Myopia, Saudi, Arabs

\section{Introduction}

Marriages between couples biologically related as second cousins or closer are considered as consanguineous relationships. [1, 2] Consanguineous marriages are a deeply rooted social culture among $20 \%$ of the world's population. $[1,2]$ This culture is mostly located in the Middle East, West Asia, and North Africa. [3, 4] Furthermore, it is found among emigrants from these communities who now reside in North America, Europe, and Australia. [3] In the Middle East, consanguinity constitutes $20-50 \%$ of all marriages; they seem to be more favorable in these communities. [5] In Saudi Arabia, the consanguinity rate is predicted to be greater than 50\%. [6-11] This high rate could be due to the belief that consanguinity may strengthen family ties, enforce family solidarity, provide an excellent opportunity for the transmission of cultural values and cultural continuity, and allows a better relationship between the in-laws. [12, 13]

Health care providers and genetics specialists have concerns that consanguineous marriage could have an impact by increasing the genetic risk of the offspring. [13-15] It has been suggested that when compared to non-consanguineous marriages, consanguinity showed a higher fertility rate, the same rate of abortions, slightly higher infant mortality rates, and slightly higher frequency of birth defects. Consanguineous unions lead to increased expression of autosomal recessive disorders. [4, 13, 16, 17] The increased risk for recessive disorders could be due to the inherited expression of autosomal recessive gene mutations from the common ancestor. Due to the autosomal recessive disorders, it have been suggested that the risk of birth defects in firstcousin marriages may be $2-2.5$ times more than that in the 
general population. [18-20] Therefore, the closer the kins are related, the greater the probability that their child will inherit identical copies of one or more detrimental recessive genes. [21] The community awareness of pathological/ genetic risks due to consanguineous unions is not at the optimum level. [22-24] Competent genetic counselling services and community-level genetic literacy interventions are greatly needed. [25-27]

There are community programs that detect carriers of hemoglobinopathies, such as thalassemia and sickle cell anemia, through the implementation of premarital screening in some middle east countries, including Saudi Arabia. [2832] However, in Saudi Arabia, $90 \%$ of couples at risk of having affected children still decided to marry; this means that any risk factor would be stand still. [33] Even if there is no history of genetic disorders in the family, first cousin marriages could double the risk of birth defects when compared to general population marriages. [19] Furthermore, there is a lack of evidence-based conclusions that establish a solid relationship between consanguinity with the late onset of complex diseases such as diabetes, cardiovascular disorders, schizophrenia, and cancer. [34] On other hands, studies are needed to assess any existing risks of consanguinity that may not have an effect until a later age. $[13,34]$ Specifically, the risk of vision impairment is among the genetic disorders that could be included in preconception genetic counseling for consanguinity. [35] This would show the presence of a genetic or hereditary disorder in the ancestors. In the field of ophthalmology, few studies have explored the relationship between consanguinity and ocular or vision disorders. Consanguinity is rarely associated with acquired blindness. [35] Further, an autosomal recessive disorder (e.g., retinitis pigmentosa) could be more common finding in populations where consanguinity is more prevalent. [17, 36-40] An increased prevalence of congenital cataracts also have been reported in those populations. [17] There are suggestions that improved screening methods (especially for refractive errors (REs)), obtaining genetic counseling, and early therapeutic interventions can reduce the effect of childhood blindness. [41]

Even though consanguineous marriages are a widespread culture in the middle east, little is known about the effect of this factor on the presence of REs in their offspring when compared to children of non-consanguineous parents. To the best of our knowledge, no study has investigated the effect of consanguinity on the incidence of REs. This study presented here was part of a bigger population studies that have been discussed and published elsewhere. [42, 43]

\section{Materials and Methods}

\subsection{Ethical Considerations}

Ethical approval was obtained from institutional ethics committee, the Ministry of Education, and all school headmasters. The Helsinki declaration was followed and parental consent forms, if needed, were collected.

\subsection{Sample Calculation and Identification}

This is a cross-sectional population based study using a multistage cluster sampling method targeted at preschoolaged children (aged 3-6 years) and adolescents (aged 12-20 years). The required sample size was calculated using EpiInfo software, version 7 (CDC, Atlanta, GA, USA; http://wwwn.cdc.gov/epiinfo/7/) based on information obtained from the Al Riyadh Directorate of Education and previous estimations of RE either in Saudi Arabia or in the Middle East region. [44, 45] The error margin was set at 5\% (with 95\% confidence interval) and the design effect was set at two using the cluster method of sampling. The minimum required sample size of the preschool-aged and adolescent groups were 280 and 644, respectively. Fourteen kindergartens and 20 highly populated intermediate and high schools from different parts of Al-Riyadh city were randomly selected.

\subsection{Determination of Visual Status}

1. Assessment of distant visual acuity (VA):

The VA was measured monocularly and corrected VA if habitual:

i. Assessment of preschool-aged children was carried out using the 15-line Lea symbols chart (Good-Lite Co., Elgin, IL, USA) at a distance of $3 \mathrm{~m}$ in a well-lit room.

ii. Adolescents' VA were measured in the logarithm of the minimum angle of resolution (logMAR) at 4 meter (non-illuminated ETDRS chart with Sloan letters, Precision Vision, La Salle, IL, USA).

2. RE assessments:

i. In preschool-aged children: Monocular RE was assessed using near-retinoscopy technique in a completely dark room. [46, 47] Previous studies have concluded that obtained RE data are significantly similar between the near-retinoscopy technique and cycloplegic retinoscopy in young children. [47-49]

ii. In the adolescent group: the RE was measured using the ARK-30 hand-held autorefractor (ARK-30; Nidek Corp., Japan). This autorefractor has not shown to be accurate and repeatable. [50] If the ARK-30 did not provide reliable readings for any reason, a distance retinoscopy was conducted.

\subsection{Data Management}

The RE was presented as the spherical equivalent (SERE). The visual status was defined as one of the following: 1) Myopic (in one or both eyes) when SERE was $\leq-0.75 \mathrm{D}$ in both groups; 2) Hyperopic when SERE was $\geq+2.00 \mathrm{D}$ in children and $\geq+1.00 \mathrm{D}$ in adolescents; 3 ) astigmatic when the cylinder power was $\geq 1.00 \mathrm{DC}$ in both groups; and 4) emmetropic when neither eye was myopic or hyperopic.

The data were analyzed separately based on the age. This was to investigate whether the effect of consanguinity was apparent during the earlier ages or later on. SPSS version 21 was used to analyze the data. The data were not normally 
distributed (Kolmogorov-Smirnov $p<0.05$ ); therefore, nonparametric tests were used where appropriate. In both groups, the SERE in the right and left eyes were comparable. The Spearman's rank test showed a strong correlation ( $r>0.95$, $p<0.05)$. Therefore, for analysis, the SERE reported in the results, in both groups, were lower than the score of the two eyes and were reported as median and inter-quartile range (IQR).

\section{Result}

\subsection{Preschool Children}

A total of 335 children were recruited. The median age [IQR] was 5 (1) years (range: 3-6 years). Approximately $87.7 \%$ of the children were emmetropic. Myopia was found in $4.2 \%$ (14 children) with a median [IQR] of $-0.88 \mathrm{D}$ [0.75 $\mathrm{D}]$ and a range of -0.50 to $-2.00 \mathrm{D}$. Hyperopia was found in $8.1 \%$ (27 children) with a median [IQR] of $+2.00 \mathrm{D}[0.50 \mathrm{D}]$, ranging from +2.00 to $+4.50 \mathrm{D}$. The astigmatism was observed in $20 \%$ (67 children) with a median [IQR] of -1.25 $\mathrm{D}[1.00 \mathrm{D}]$ and range from -1.00 to $-3.00 \mathrm{D}$ (Table 1). Finally, severe myopia (SERE $=-10.00 \mathrm{D},-13.50 \mathrm{D}$, and $17.50 \mathrm{D})$ was found in three children. Those children were analyzed separately as they were treated as statistical outliers.

\subsection{Adolescents}

A total of 998 adolescents were recruited. The participants' age ranged from 12 to 20 years (median [IQR] $=16$ (3) years). Ametropia was observed in 49.4\% (493 participants) of the participants. The majority of the ametropic condition was myopia (455 students [45.6\%] with a median and [IQR] of $-1.12 \mathrm{D}$ [1.54] ranging from $0.75 \mathrm{D}$ to $-14.50 \mathrm{D})$ and $3.8 \%(38)$ were hyperopic $(1.87 \mathrm{D}$ [1.5] ranging from $1.00 \mathrm{D}$ to $4.75 \mathrm{D})$, while $223(22.3 \%)$ were astigmatic $(-0.50 \mathrm{D}[0.50])$ ranging from $1.00 \mathrm{DC}$ to 5.00 DC) (Table 1).

Table 1. The types, frequencies, and severity of the encountered refractive errors (RE) in the preschool and adolescent groups.

\begin{tabular}{|c|c|c|c|c|}
\hline Group & $\mathbf{R E}$ & Low $(R E \leq 3 \mathrm{D})$ & Moderate (3 D $<$ RE $\leq 6$ D) & High $($ RE $>6$ D) \\
\hline Preschool & \multirow{2}{*}{ Myopia $\leq 0.75 \mathrm{D}$} & $14(4.2 \%)$ & $0 \%$ & $3(0.90)$ \\
\hline Adolescents & & $344(34.5 \%)$ & $98(9.8 \%)$ & $13(1.3 \%)$ \\
\hline Preschool & Hyperopia $\geq+2.00 \mathrm{D}$ & $19(7.3 \%)$ & $8(0.80 \%)$ & $0 \%$ \\
\hline Adolescents & Hyperopia $\geq+1.00 \mathrm{D}$ & $30(3 \%)$ & $8(0.80 \%)$ & $0 \%$ \\
\hline Preschool & \multirow{2}{*}{ Astigmatism $\geq 1.00 \mathrm{DC}$} & $67(20 \%)$ & $\% 0$ & $\% 0$ \\
\hline Adolescents & & $207(20.7 \%)$ & $16(1.6 \%)$ & $0 \%$ \\
\hline
\end{tabular}

\subsection{Consanguinity and Relationship of REs}
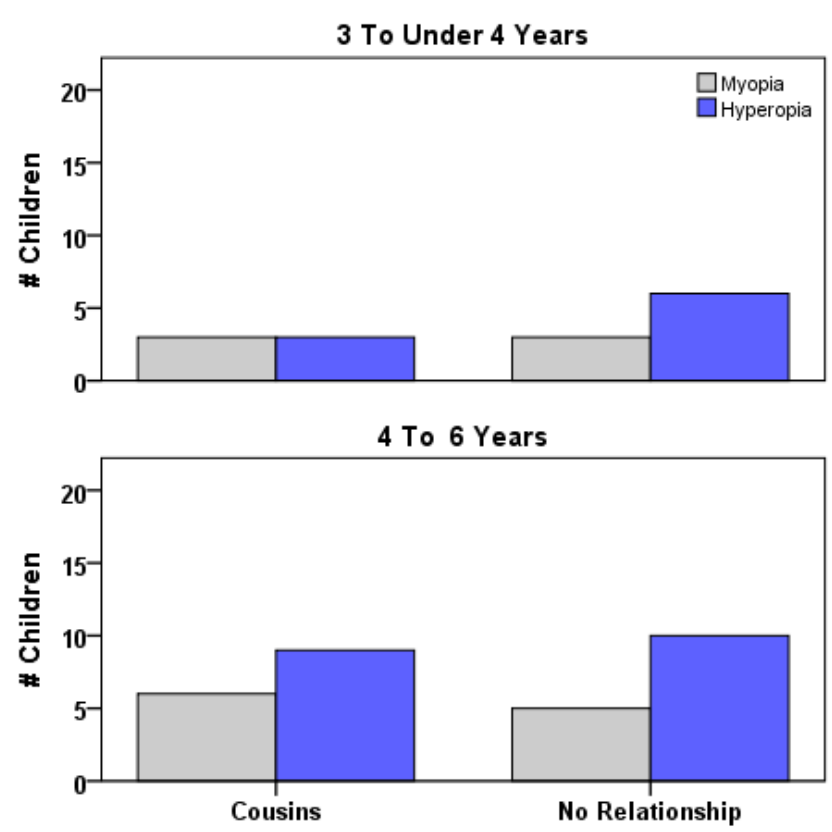

Figure 1. Frequencies of refractive errors in preschooler children with parents whom cousins and with parents with no such relationships.

In the preschool group, approximately $42 \%$ were children of married cousins and 58\% had no such relationship (ratio = $1: 1.4)$. In the adolescent group, the ratio was $1.1: 1(51.5 \%$ cousins and $48.5 \%$ with no relationship). In both groups, it has been shown that consanguinity did not have an impact on the prevalence or the type of RE (ANOVA Test, $p>0.05$ ) (Figures 1-4), despite being slightly more frequent in children 15 years and older in the cousin groups. It was also evident in the three children with high myopia in the preschooler group (Figures 3-4).
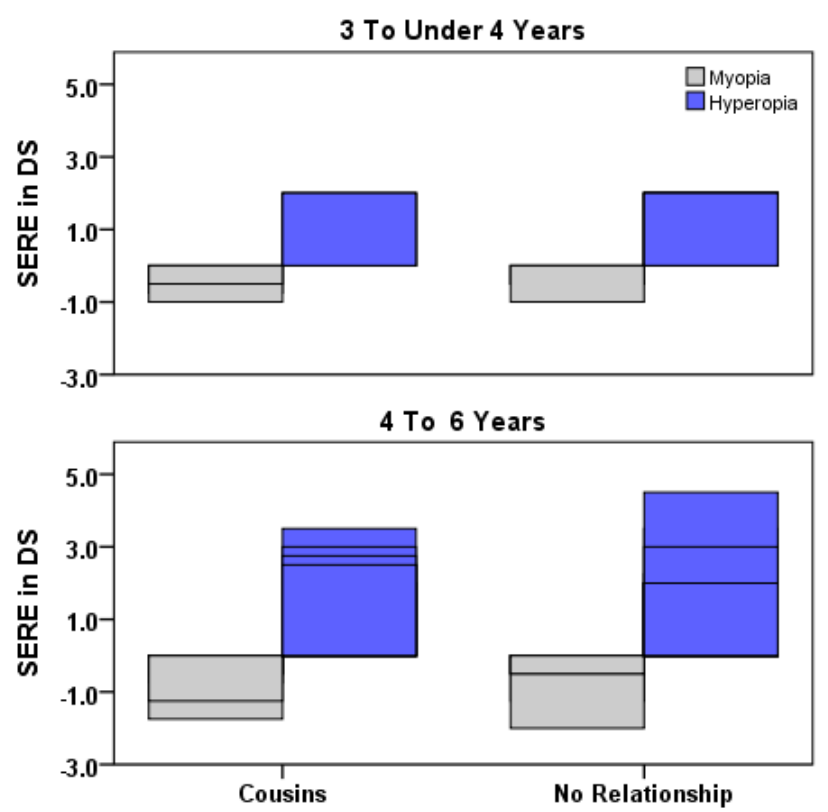

Figure 2. The spherical equivalents of preschooler refractive errors in parents with cousins' relationship or otherwise. 


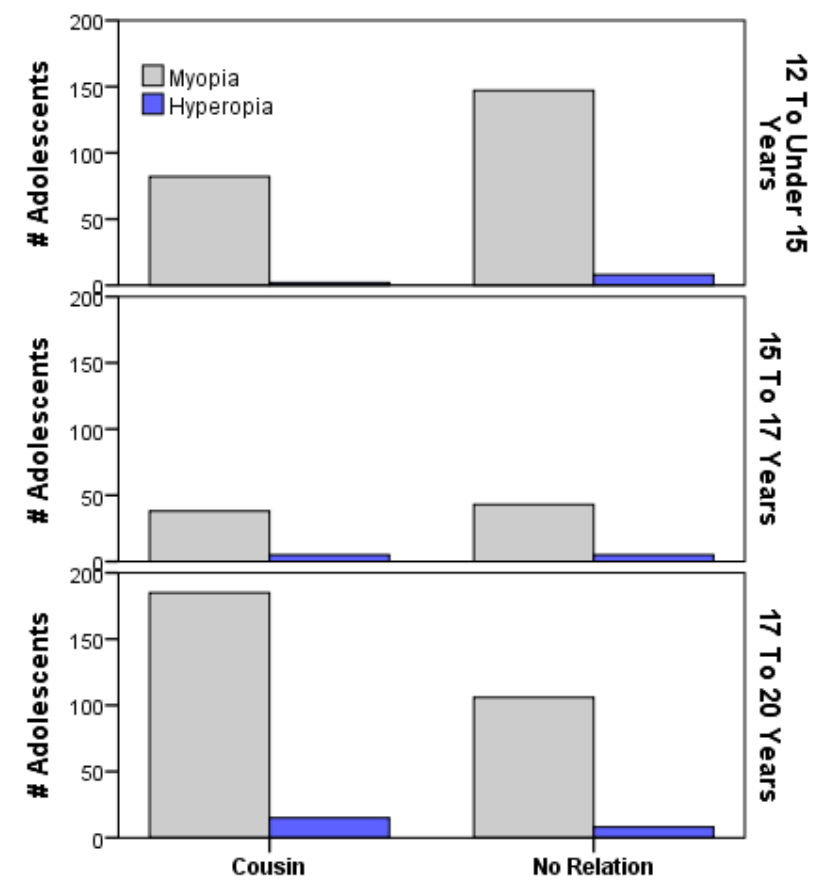

Figure 3. Frequencies of refractive errors in adolescents' participants divided based on the parents relationship to each other.

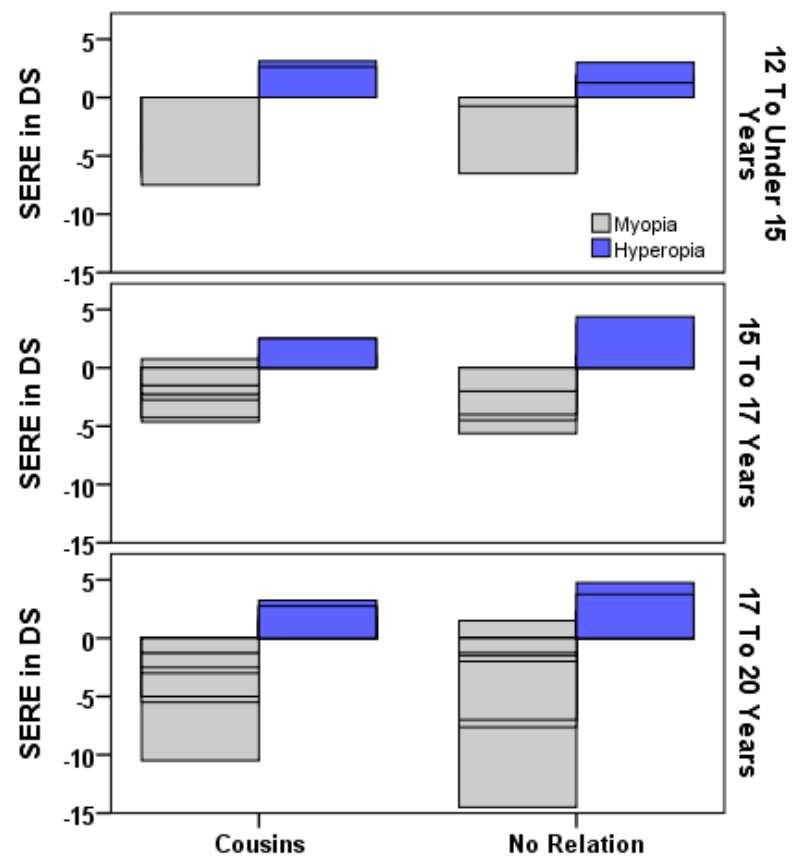

Figure 4. The spherical equivalents of refractive errors in adolescents' participants in both subgroups.

\section{Discussion}

There are few studies on the prevalence of an ocular disorder due to consanguinity. Specifically, there have been concerns that the ocular disorders exhibited by some groups of the Saudi population could be due to consanguinity. However, without evidence-based conclusions, one cannot assume that consanguinity inevitably causes a high percentage of autosomal recessive diseases or ocular disorders, but a higher risk for ocular disorders can be expected. For example, Reddy et al. (2008) found that $22 \%$ of a ocular genetic conditions sample had a history of consanguinity. [51] However, in their study, they did not include REs in their investigations. Nirmalan et al. (2006) conducted a larger population-based study (10290 children) and found that only $0.008 \%$ of the children had an ocular disease with a potential genetic cause. [52] However, it has been found that blind children with genetic diseases had significantly higher incidence of parental consanguinity than children in the group with acquired diseases. [53, 54] Furthermore, primary congenital glaucoma is more common in populations with a higher prevalence of consanguinity. [55] Yang $\mathrm{Z}$ et al. (2009) suggested that an autosomal recessive gene is responsible for severe myopia in a consanguineous Chinese family. Finally, some studies suggested that there may be a link between consanguinity and strabismus. [56, 57]

In this study, the prevalence of myopia increased with increased age (with 10 -fold increase from $4.2 \%$ to $45 \%$ ). In contrast, a decrease in the prevalence of hyperopia was also observed with an increase in age (a decrease by 50\% from $8.1 \%$ to $3.8 \%$ ). However, a similar percentage of astigmatism was noted in both groups (approximately 20\%). Our result was consistent with the prevalence of myopia found in previous studies, [58-61] which is also consistent with the result found in Saudi Arabia. [62]

In this study, the link between consanguinity and REs was investigated at two cross-sectional points of the participants' life. The first period was between the ages of 3 and 6 years, which is the period of active vision development. The second period was between 12 and 20 years of age, which is the period vision presumably maturely develops. In both groups, the recruited participants had almost the same ratio of parents who were and were not cousins. This result could provide two merits to this study. First, the participants were recruited at random, and therefore, the results are not biased. This result also could indicate that the consanguinity is a widespread culture in the Saudi community, as it has been previously suggested. [6-11] Second, since approximately half of the participants had a kinship relationship, whereas the other half did not, this sampling structure could bring to light any effect of the consanguinity factor. RE was more frequent in the cousin groups after 15 years of age and was also found in the preschool children with severe myopia (Figures 3-4). However, this did not show a statistically significant impact of the consanguinity factor. This result suggests that although ocular genetic disorders or congenital glaucoma could be linked to consanguinity, [51-55] no evidence was found to link REs to consanguinity.

\section{Conclusion}

The aim of this study was to investigate the effects of consanguineous marriages on the refractive errors of preschool-aged and adolescent participants. The finding of 
this study suggested that there was no statistical and/or clinical evidence that parents whom are relatives have a significant effect on the type or severity of REs. However, studies with larger sample sizes are required to further explore the strength of this effect.

\section{Conflict of Interest}

The authors declare that they have no competing interests.

\section{Acknowledgements}

The authors extend their appreciation to the College of Applied Medical Sciences Research Centre and the Deanship of Scientific Research at King Saud University for funding this research. The author would like also to extend the appreciation to all participants, parents, school staff and to all whom facilitate this work without them this work was not possible.

\section{References}

[1] Bhinder MA, Sadia H, Mahmood N, et al. Consanguinity: A blessing or menace at population level? Annals of Human Genetics. 2019; 83: 214-9.

[2] Bittles AH. The Role and Significance of Consanguinity as a Demographic Variable. Population and Development Review. 1994; 20: 561-84.

[3] Bittles AH, Savithri HS, Venkatesha Murthy HS, Baskaran G, Wang $\mathrm{W}$ and Cahill J. Human inbreeding: a familiar story full of surprises. In: Macbeth $\mathrm{H}$ and Shetty P, (eds.). Ethnicity and Health. London: Taylor and Francis., 2001, p. 68-78.

[4] Tadmouri GO, Nair P, Obeid T, Al Ali MT, Al Khaja N and Hamamy HA. Consanguinity and reproductive health among Arabs. Reproduct Health. 2009; 6: 17.

[5] Islam MM, Ababneh FM and Khan MDHR. CONSANGUINEOUS MARRIAGE IN JORDAN: AN UPDATE. Journal of Biosocial Science. 2018; 50: 573-8.

[6] Bittles A. The global prevalence of consanguinity.

[7] $\mathrm{Al}$ Husain $\mathrm{M}$ and $\mathrm{Al}$ Bunyan $\mathrm{M}$. Consanguineous marriages in a Saudi population and the effect of inbreeding on prenatal and postnatal mortality. Ann Trop Paediatr. 1997; 17: 155-60.

[8] Al-Abdulkareem AA and Ballal SG. Consanguineous marriage in an urban area of Saudi Arabia: rates and adverse health effects on the offspring. J Community Health. 1998; 23: 75-83.

[9] Saedi-Wong S and al-Frayh AR. Effects of consanguineous matings on anthropometric measurements of Saudi newborn infants. Fam Pract. 1989; 6: 217-20.

[10] el-Hazmi MA, al-Swailem AR, Warsy AS, al-Swailem AM, Sulaimani R and al-Meshari AA. Consanguinity among the Saudi Arabian population. J Med Genet. 1995; 32: 623-6.

[11] El-Mouzan MI, Al-Salloum AA, Al-Herbish AS, Qurachi MM and Al-Omar AA. Regional variations in the prevalence of consanguinity in Saudi Arabia. Saudi Med J. 2007; 28: 1881-4.
[12] Sandridge AL, Takeddin J, Al-Kaabi E and Frances Y. Consanguinity in Qatar: knowledge, attitude and practice in a population born between 1946 and 1991. J Biosoc Sci. 2009; 42: 59-82.

[13] Hamamy H, Antonarakis SE, Cavalli-Sforza LL, et al. Consanguineous marriages, pearls and perils: Geneva International Consanguinity Workshop Report. Genet Med. 2011; 13: 841-7.

[14] Oniya O, Neves K, Ahmed B and Konje JC. A review of the reproductive consequences of consanguinity. European Journal of Obstetrics \& Gynecology and Reproductive Biology. 2019; 232: 87-96.

[15] Hemant CS and Huchechesha K. CONSANGUINITY AND RISK OF CONGENITAL DEFECTS- A SYSTEMATIC REVIEW. Journal of Evolution of Medical and Dental Sciences-Jemds. 2018; 7: 3552-9.

[16] Bittles A, Mason W, Greene J and Rao N. Reproductive behavior and health in consanguineous marriages. Science. 1991; 252: 789-94.

[17] Bittles AH and Black ML. The impact of consanguinity on neonatal and infant health. Early Hum Dev. 2010; 86: 737-41.

[18] Jaber L, Halpern GJ and Shohat M. The impact of consanguinity worldwide. Community Genet. 1998; 1: 12-7.

[19] Stoltenberg C, Magnus P, Lie RT, Daltveit AK and Irgens LM. Birth defects and parental consanguinity in Norway. Am J Epidemiol. 1997; 145: 439-48.

[20] Bromiker R, Glam-Baruch M, Gofin R, Hammerman C and Amitai Y. Association of parental consanguinity with congenital malformations among Arab newborns in Jerusalem. Clin Genet. 2004; 66: 63-6.

[21] Bennett RL, Motulsky AG, Bittles A, et al. Genetic counseling and screening of consanguineous couples and their offspring: recommendations of the National Society of genetic Genetic Counselors. J Genet Couns. 2002; 11: 97-119.

[22] Teeuw ME, Loukili G, Bartels EAC, ten Kate LP, Cornel MC and Henneman L. Consanguineous marriage and reproductive risk: attitudes and understanding of ethnic groups practising consanguinity in Western society. European Journal of Human Genetics. 2014; 22: 452-7.

[23] Lima SOA, Farias AA, Albino VA, et al. A population-based study of inter-generational attitudes towards consanguineous marriages in north-eastern Brazil. Journal of Biosocial Science. 2019; 51: 683-97.

[24] Josephi-Taylor S, Barlow-Stewart K, Selvanathan A, et al. User Acceptability of Whole Exome Reproductive Carrier Testing for Consanguineous Couples in Australia. Journal of Genetic Counseling. 2019; 28: 240-50.

[25] Salway S, Ali P, Ratcliffe G, et al. Responding to the increased genetic risk associated with customary consanguineous marriage among minority ethnic populations: lessons from local innovations in England. Journal of Community Genetics. 2016; 7: 215-28.

[26] Darr A, Small N, Ahmad WIU, Atkin K, Corry P and Modell B. Addressing key issues in the consanguinity-related risk of autosomal recessive disorders in consanguineous communities: lessons from a qualitative study of British Pakistanis. Journal of Community Genetics. 2016; 7: 65-79. 
[27] Thain E, Shuman C, Miller K, et al. Prenatal and preconception genetic counseling for consanguinity: Consanguineous couples' expectations, experiences, and perspectives. Journal of Genetic Counseling. 2019; 28: 98292.

[28] Memish ZA and Saeedi MY. Six-year outcome of the national premarital screening and genetic counseling program for sickle cell disease and $\beta$-thalassemia in Saudi Arabia. Ann Saudi Med. 2011; 31: 229-35.

[29] Hamamy H, Al-Hait S, Alwan A and Ajlouni K. Jordan: communities and community genetics. Community Genet. 2007; 10: 52-60.

[30] Al-Allawi NA and Al-Dousky AA. Frequency of haemoglobinopathies at premarital health screening in Dohuk, Iraq: implications for a regional prevention programme. East Mediterr Health J. 2010; 16: 381-5.

[31] Al Arrayed S. Campaign to control genetic blood diseases in Bahrain. Community Genet. 2005; 8: 52-5.

[32] Mendilcioglu I, Yakut S, Keser I, et al. Prenatal diagnosis of beta-thalassemia and other hemoglobinopathies in southwestern Turkey. Hemoglobin. 2011; 35: 47-55.

[33] Alswaidi FM, Memish ZA, O'Brien SJ, et al. At-risk marriages after compulsory premarital testing and counseling for beta-thalassemia and sickle cell disease in Saudi Arabia, 2005-2006. J Genet Couns. 2012; 21: 243-55.

[34] Gurdasani D, Barroso I, Zeggini E and Sandhu MS. Genomics of disease risk in globally diverse populations. Nature Reviews Genetics. 2019; 20: 520-35.

[35] Kemmanu V, Giliyar SK, Rao HL, Shetty BK, Kumaramanickavel G and McCarty CA. Consanguinity and its association with visual impairment in southern India: the Pavagada Pediatric Eye Disease Study 2. J Community Genet. 2019; 10: 345-50.

[36] Kumaramanickavel G, Joseph B, Vidhya A, Arokiasamy T and Shridhara Shetty N. Consanguinity and ocular genetic diseases in South India: analysis of a five-year study. Community Genet. 2002; 5: 182-5.

[37] Akkaya S. Rate of parental consanguineous marriage among patients with visual impairments in Turkey. Med Hypothesis Discov Innov Ophthalmol. 2016; 5: 115-20.

[38] Tabbara KF and Badr IA. Changing pattern of childhood blindness in Saudi Arabia. Brit J Ophthalmol. 1985; 69: 31215 .

[39] den Hollander AI, Lopez I, Yzer S, et al. Identification of novel mutations in patients with leber congenital amaurosis and juvenile RP by genome-wide homozygosity mapping with SNP microarrays. Invest Ophthalmol Vis Sci. 2007; 48: 569098 .

[40] Schwarz K, Yeung S, Symons N and Bradbury J. Survey of school children with visual impairment in Bradford. Eye. 2002; 16: 530-4.

[41] Bandrakalli P, Ganekal S, Jhanji V, Liang YB and Dorairaj S. Prevalence and causes of monocular childhood blindness in a rural population in southern India. $J$ Pediatr Ophthalmol Strabismus. 2012; 49: 303-7.

[42] Alsaqr AM, Ibrahim G, Sharha AA and Fagehi R.
Investigating the Visual Status Of Preschool Children in Riyadh, Saudi Arabia. Middle East Afr J Ophthalmol. 2017; 24: 190-4.

[43] Alsaqr AM, Abu Sharha A, Fagehi R, et al. The visual status of adolescents in Riyadh, Saudi Arabia: a population study. Clin Ophthalm. 2018; 12: 965-72.

[44] Bardisi WM and Bin Sadiq BM. Vision screening of preschool children in Jeddah, Saudi Arabia. Saudi Med J. 2002; 23: 4459.

[45] Yamamah GAN and Mohammed AM. Prevalence of visual impairment and refractive errors in children of south Sinai, Egypt. Ophthalmic Epidemiol. 2015; 22: 357.

[46] Mohindra I. Non-cycloplegic refraction technique for infants and young-children. J Am Optom Assoc. 1977; 48: 518-23.

[47] Mohindra I and Molinari J. Near retinoscopy and cycloplegic retinoscopy in early primary grade schoolchildren. $A m J$ Optom Physiol Opt. 1979; 56: 34-8.

[48] Borghi RA and Rouse MW. Comparison of refraction obtained by near retinoscopy and retinoscopy under cycloplegia. $\mathrm{Am} \mathrm{J}$ Optom Physiol Opt. 1985; 62: 169-72.

[49] Saunders K and Westall C. Comparison between near retinoscopy and cycloplegic retinoscopy in the refraction of infants and children. Optom Vis Sci. 1992; 69: 615-22.

[50] de Juan V, Herreras JM, Martin R, et al. Repeatability and agreement of ARK-30 autorefraction after cataract surgery. Clin Exp Ophthalmol. 2012; 40: 134-40.

[51] Reddy MA, Purbrick R and Petrou P. The prevalence of patients with ocular genetic disorders attending a general paediatric ophthalmology clinic in the East End of London. Eye. 2008; 23: 1111-4.

[52] Nirmalan PK, Krishnaiah S, Nutheti R, Shamanna BR, Rao GN and Thomas R. Consanguinity and eye diseases with a potential genetic etiology. Data from a prevalence study in Andhra Pradesh, India. Ophthalmic Epidemiol. 2006; 13: 713.

[53] Tabbara KF. Blindness in the eastern Mediterranean countries. Brit J Ophthalmol. 2001; 85: 771-75.

[54] al-Salem M and Rawashdeh N. Pattern of childhood blindness and partial sight among Jordanians in two generations. $J$ Pediatr Ophthalmol Strabismus. 1992; 29: 361-5.

[55] Ko F, Papadopoulos M and Khaw PT. Primary congenital glaucoma. In: Bagetta $\mathrm{G}$ and Nucci C, (eds.). New Trends in Basic and Clinical Research of Glaucoma: A Neurodegenerative Disease of the Visual System, Pt B. 2015, p. 177-89.

[56] Bagheri M, Farvardin $M$ and Saadat M. A study of consanguineous marriage as a risk factor for developing comitant strabismus. J Community Genet. 2015; 6: 177-80.

[57] Khan AO, Shinwari J, Al Sharif L, Khalil D, Al-Gehedan S and Al Tassan NA. Infantile esotropia could be oligogenic and allelic with Duane retraction syndrome. Mol Vis. 2011; 17: 1997-2002.

[58] Matsumura $\mathrm{H}$ and Hirai $\mathrm{H}$. Prevalence of myopia and refractive changes in students from 3 to 17 years of age. Surv of Ophthalmol. 1999; 44: S109-S15. 
[59] Lin LLK, Shih YF, Hsiao CK and Chen CJ. Prevalence of myopia in Taiwanese schoolchildren: 1983 to 2000. Ann Acad Med Singapore. 2004; 33: 27-33.

[60] Giordano L, Friedman D, Repka M, et al. Prevalence of refractive error among preschool children in an urban population: The Baltimore Pediatric Eye Disease Study. Ophthalmology. 2009; 116: 739-46.
[61] Williams KM, Bertelsen G, Cumberland P, et al. Increasing prevalence of myopia in Europe and the impact of education. Ophthalmology. 2015; 122: 1489-97.

[62] Al-Rowaily MA. Prevalence of refractive errors among preschool children at King Abdulaziz Medical City, Riyadh, Saudi Arabia. Saudi J Ophthalmol. 2010; 24: 45-8. 